\title{
A continuance model for optimized participation in virtual communities
}

\begin{abstract}
The social commerce wave has opened up vast opportunities in emerging markets through virtual communities' participation. This chapter investigates the constructs and theories from the social psychology perspective looking into the intention and behaviour prospect by extending the Theory of Planned Behaviour (TPB) and integrating the Social Support Theory (SST) to purport a continuance model for virtual communities' optimized participation in Malaysia. The model uncovers that the emotional and informational constructs of the SST and constructs of the TPB as well as perceived value optimizes participation. This chapter also establishes a continuance model and illustrates how theory from the social psychology literature positions the constructs of SST, TPB and perceived value in enhancing the participation of virtual communities. The SEM-PLS method used to analyse the data shows that the intention and behaviour of the virtual communities determine users' participation level. Furthermore, this chapter seeks to enlighten our knowledge on virtual communities and tap into the social commerce capabilities.
\end{abstract}

